\title{
Impact of a Strength Intervention Program on Change of Hamstrings: Quadriceps Ratio and on Change of 1 Repetition Maximum
}

\author{
Tereza Hammerová', Tereza Králová', Jan Cacek', Tomáš Kalina', Zuzana Hlavoňová', Jan Ondráček' \\ ${ }^{1}$ Faculty of Sports Studies, Masaryk University
}

\begin{abstract}
The relationship between the muscular strength of hamstrings and quadriceps and their possible muscular imbalance is considered by many authors as one of the causes of knee joint injury. The aim of this work is to assess the exercise program including squat modifications both in terms of progression of lower limb strength and in terms of possible change of $\mathrm{H}: \mathrm{Q}$ ratio. Probands were divided into five groups (one control, four experimental). The experimental groups practiced the intervention program twice a week for eight weeks (EX1: Barbell squat, EX2: Barbell half squat, EX3: Barbell half squat with countermovement). In one training session participants repeated the exercise five times in six series. All experimental groups exhibited significant differences in mean values $(p<0.01)$, indicating the progression of lower limb strength measured by $1 R M$ for barbell squat. The differences in the mean values of the H: $Q$ ratio measured on an isokinetic dynamometer in the isokinetic test mode at angular velocities of 60 and 300 degrees per second do not show statistically significant differences ( $p=0.99338$ ). The established strength intervention program is suitable for the development of lower limb strength and does not show any changes in the $\mathrm{H}$ : $\mathrm{Q}$ ratio.
\end{abstract}

Key words: Squat, Strength, Hamstrings, Quadriceps, 1 RM, ACL, Isokinetic dynamometer

\section{INTRODUCTION}

Sports performances are constantly moving forward. Increasing demands are required from athletes. For all kind of sports, it is essential for athletes to be well prepared for any performance. Good physical condition is necessary not only to win, but also to prevent possible injuries. If an athlete needs to be musculous, it is necessary to include in their own training program also properly designed strength training. Possible muscle imbalances can cause injuries. In the case of lower limbs, the literature focuses on the ratio of hamstrings and quadriceps $(\mathrm{H}: \mathrm{Q})$.

We approach the $\mathrm{H}$ : $\mathrm{Q}$ ratio from two perspectives, depending on the type of muscle contraction during which maximum strength is produced. If both muscle groups work at concentric muscle contraction, it is the conventional $\mathrm{H}_{\text {con }}: \mathrm{Q}_{\text {con }}$ ratio. If the hamstrings muscle group works in eccentric muscle contraction and the quadriceps muscle group in concentric muscle contraction, it is a functional $\mathrm{H}_{\text {ecc }}: \mathrm{Q}_{\text {con }}$ ratio (Delextrat, Gregory, \& Cohen 2010).

Both the strength of the quadriceps and the strength of the hamstrings are very important for the stability of the knee joint (Tsepis, Vagenas, Giakas, \& Georgoulis, 2004). Low H: Q ratio can be considered as an indicator of hamstrings injury or anterior cruciate ligament (ACL) injury. For the conventional $\mathrm{H}_{\text {con }}: \mathrm{Q}_{\text {con }}$ ratio, the critical value is set at 0.6 . For the functional ratio $\mathrm{H}_{\text {ecc }}: \mathrm{Q}_{\text {con }}$, the critical value is set at 1.0. Data should be obtained from measurements at a rate of at least 120 degrees per second. If the athlete shows a lower H: Q ratio than the stated limit values, the specialist should create an exercise program to eliminate muscle imbalance as well as to establish proper cooperation of the agonist and antagonist. Women are more likely to have injuries, so their physical condition should be monitored more thoroughly. (Holcomb, Rubley, Lee, \& Guadagnoli, 2007). 
Squat is being considered a basic exercise for the development of lower limb strength (Cacek, \& Grasgruber, 2008; Stoppani, 2008). Mausehund, Skard, \& Krosshaug (2019) compared three types of lower limb strength exercises. Specifically, it was split squat (SS), rear foot elevated split squat (RFESS), and single-leg squat (SLS). The exercises show a strength increase in all selected muscle groups. Muscle strength of gluteus maximus and quadriceps increases similarly in all the applied exercises. The SLS achieves the highest power gain in the gluteus medius. It is convenient to include the RFESS in the exercise plan for hamstrings. The SS, SLS and especially RFESS should be included in the recovery program for injury or reconstruction of ACL.

For this work was developed a strength program aimed at strengthening muscle groups in the lower limbs, which includes only squats. We will investigate whether the program is effective in increasing strength and whether the conventional $\mathrm{H}$ : Q ratio will change significantly after its application. Selected modifications of squat exercises will be assigned to 4 experimental groups. These are the exercises: barbell squat, barbell half squat, barbell squat with countermovement and barbell half squat with countermovement. The load will also be manipulated. For exercises involving countermovement, the load will be around 30\% 1RM, for exercises without countermovement around 95\% 1RM.

\section{METHODS}

\section{Subjects}

Male students of Faculty of Sports Studies (Masaryk University) participated in the strength intervention. They were randomized into five homogeneous groups (four experimental, one control). Using One-Way ANOVA, we compared the mean values of the experimental groups (categorical factor: EX1-EX4) from several perspectives (dependent variables: H: Q ratio obtained from the dynamometer data at an angular speed of 60 as well as 300 degrees per second and 1RM of barbell squat). For all testing, we received $p>\alpha$. Before the subjects were chosen the following factors were considered: age, body weight, no rupture of the anterior cruciate ligament (ACL), no health complications. The experimental groups consisted of a total of 40 persons $(\mathrm{N}=40)$ and their average age was $22.06 \pm 2.17$ years. Since the strength intervention involved squats (full squat and half squat), it was necessary to train all tested persons. The correct technique of squat is very important, which is why everybody was trained by an expert before the start of the intervention.

\section{Study design}

The purpose of the study was comparing the strength (through different parameters, e.g. measuring $1 \mathrm{RM}$ and data from isokinetic dynamometer) and values of hamstrings: quadriceps ratio before and after strength intervention program.

Participants were trained by Czech weightlifting team members in the correct technique of squat to ensure safety during both measurement and exercise part of the intervention program. We created appropriate exercises to warm up and stretch the muscles and we made sure that the participants followed them. All trainees had assistants at all time due to the safety reasons.

In the detection of 1RM of barbell squat, the test subjects did not exercise with the maximum load, but with the load they lifted e.g. four or five times in the barbell squat. The resulting values were consequently calculated according to the formulas by Brzycki and Baechle (Baechle, \& Earle, 2008).

Knee joint muscles were diagnosed on a dynamometer (Humac Norm, CSMI, Stoughton, USA). Isokinetic testing, the range of motion was $0^{\circ}-125^{\circ}\left(0^{\circ}\right.$ is the maximum extension in the knee joint) at angular velocities of $60^{\circ}$ per second and $300^{\circ}$ per second. Testing of each person was carried out in a sitting position, with straps fixed over the shoulders, pelvis and quadriceps of the test leg exactly according to the manufacturer's recommendations. The software of this 
instrument enables writing anatomical values to define the position of each testing person on the machine, the data were recorded and the same position was automatically set for each one during the post-tests. All the tested subjects were measured by an identical person. Since both tests were very demanding (1RM and dynamometer testing) it was essential to perform them forty-eight hours apart. The tests were performed before the intervention (pre-test), 1RM values were measured after four weeks when the participants' load was updated, and post-tests were made after eight-week intervention.

The protocol (Fig. 1) of this study includes a timing of measurements and a schedule of strength interventions for each of the experimental groups.

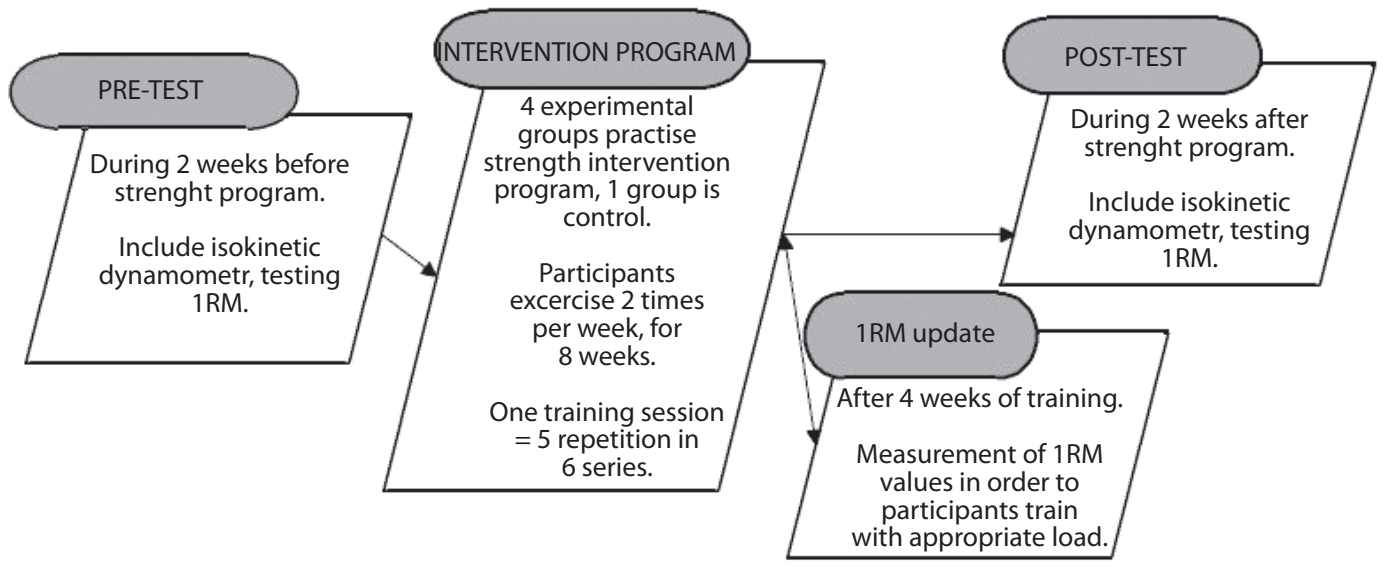

Fig. 1: The protocol of timing of measurements and strength interventions schedule

Participants were randomized into five groups, four experimental groups and one group was a control group. Participants in selected experimental groups underwent strength training equally twice a week, forty-eight hours apart for recovery. However, their program and load were different as shown in Tab. 1. Knee joint angle of 90 degrees became a critical point in determining the difference between a squat and a half squat (Chelly et al., 2010). Within one intervention, the test subjects practiced six series with five repetitions of the exercise (Tan, 1999).

Tab. 1: Type of squats and loads for all groups

\begin{tabular}{|l|l|l|}
\hline Group & Type of squat & Load \\
\hline Experimental group 1 (EX 1) & Barbell squat & 95\% 1RM \\
\hline Experimental group 2 (EX 2) & Barbell half squat & 95\% 1RM \\
\hline Experimental group 3 (EX 3) & Barbell squat with countermovement & $30 \% 1 \mathrm{RM}$ \\
\hline Experimental group 4 (EX 4) & Barbell half squat with countermovement & $30 \% 1 \mathrm{RM}$ \\
\hline Control group (CON) & - & - \\
\hline
\end{tabular}

\section{Statistical analysis}

Repeated measures analysis of variance with effect sizes and powers were used to compare the change in 1RM values before, during, and after the intervention. Evaluation of the H: Q ratio 
before and after the intervention was performed with two-way ANOVA with repeated measures. Significance was accepted at the $p \leq 0.05$ level.

\section{RESULTS}

\section{Results from measurements of $1 R M$}

The comparison of the mean values of the experimental groups (EX1-EX4) obtained before the intervention, after four weeks of intervention and after eight weeks when the intervention was finished, can be observed in Fig. 2. Considering the value $p=0.00489$ we can find a statistically significant difference of all mean values $\left(\eta_{\mathrm{p}}{ }^{2}=0,222\right)$. Although we determine a significant difference between the mean values through ANOVA calculations, the post hoc test, resp. Bonferroni test confirming that statistically significant differences occur in each experimental group during measurement.

TIME* group; Unweighted Means

Current effect: $F(6,72)=3,4327, p=, 00489$

Effective hypothesis decomposition

Vertical bars denote 0,95 confidence intervals

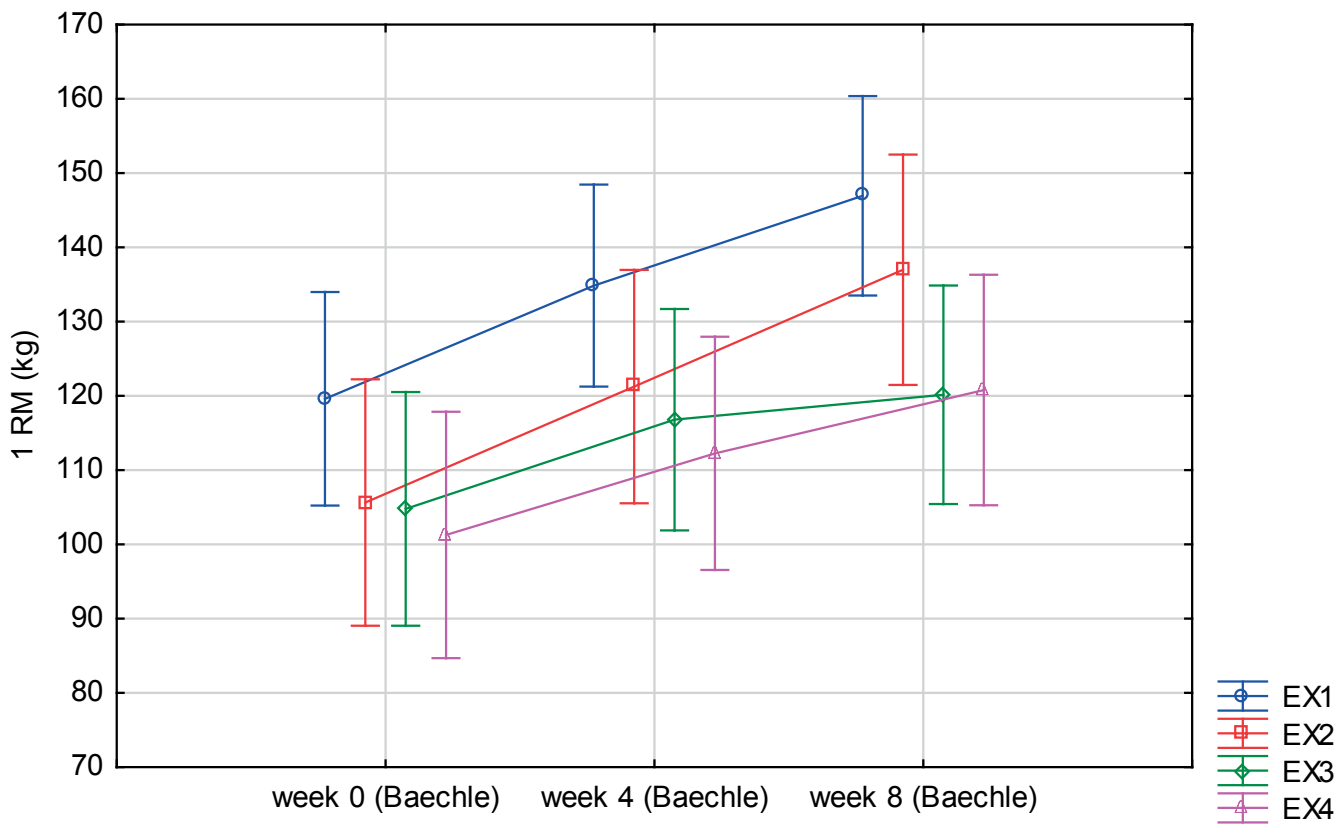

Fig. 2: The Changes of $1 \mathrm{RM}$ values due to the intervention strength program

\section{Results from measurements $H_{c o n}: Q_{\text {con }}$ ratio}

The data obtained from isokinetic testing of lower limb is suitable for calculating the conventional $\mathrm{H}_{\text {con }}: \mathrm{Q}_{\text {con }}$ ratio. It can be seen from Fig. 3 that the $\mathrm{H}_{\text {con }}: \mathrm{Q}_{\text {con }}$ ratio achieves on average higher values when measured at a higher angular velocity. After statistical data processing (two-way ANOVA with repeated measures), it is obvious that the mean values do not show statistically significant differences with a probability of $p=0.99338$. The selected strength program does not increase or reduce the $\mathrm{H}_{\text {con }}: \mathrm{Q}_{\text {con }}$ ratio. It can also be seen from the graph (Fig. 3) that the $\mathrm{H}_{\text {con }}: \mathrm{Q}_{\text {con }}$ values 
are very low. At an angular velocity of 60 degrees per second, the mean values of all groups (preand post-intervention) fall below the 0.60 level. Such a low value can cause ACL or hamstrings injuries (Hammerová, Králová, Cacek, Kalina, Hlavoňová, \& Ondráček, 2018).

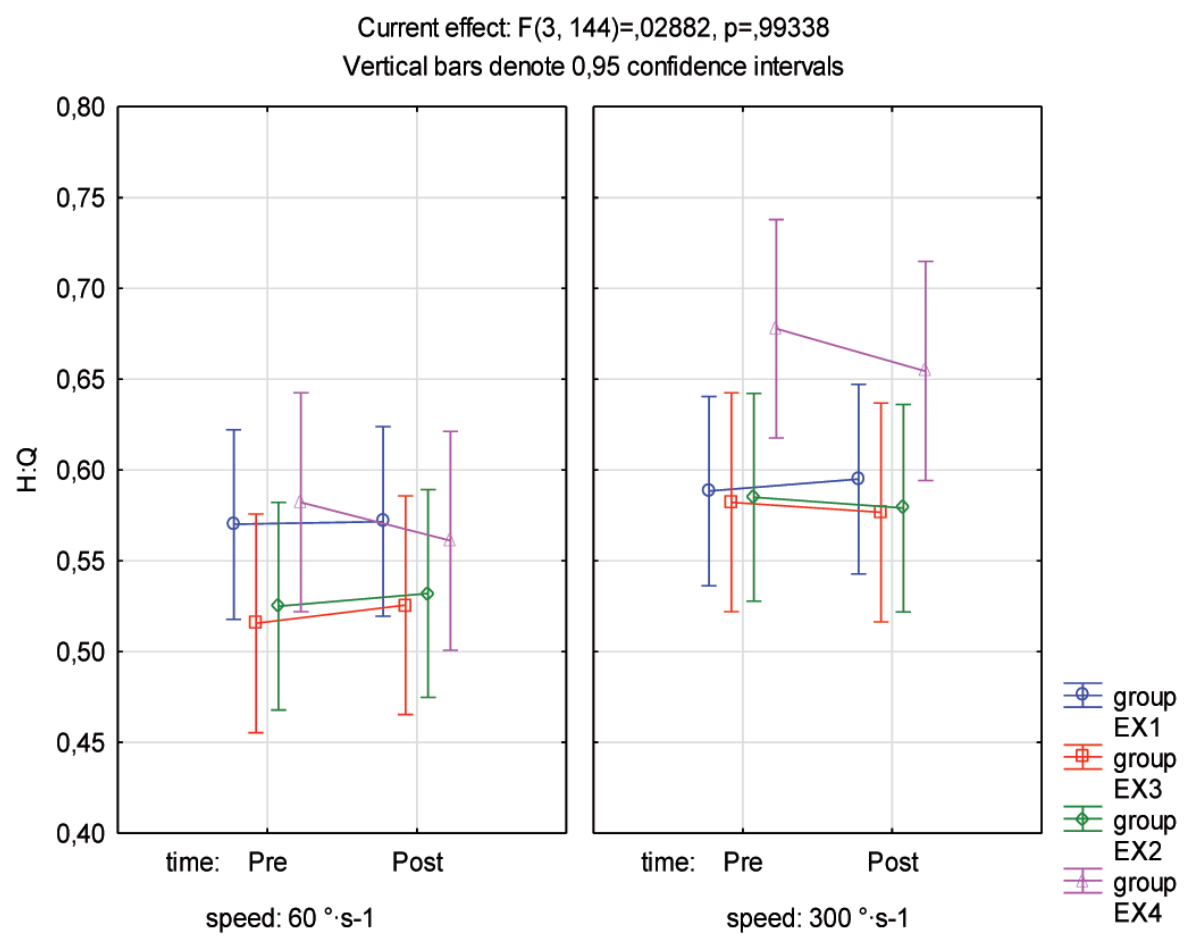

Fig. 3: The Changes of Hcon: Qcon ratio due to the intervention strength program

\section{DISCUSSION}

Many athletes use squats in their training programs. However, it is true that many athletes also have health problems with the knee joint or problems with selected muscle groups. Therefore, it is necessary to consider both the benefits and potential risks of selected exercises. Toutoungi, Lu, Leardini, Catani, \& O'Connor (2000) report that squats should be safer for ACL than isokinetic or isometric extension to develop the strength of quadriceps. At the same time, they say that isokinetic and isometric flexion can be safely used to develop the strength of hamstrings. Considering the forces exerted on the knee joint and all its structures, the inclusion of a squat in the training program should not be harmful to the ACL.

Also, the results of our research show that although there was a statistically significant increase in lower limb strength (values of 1RM) in all experimental groups, they did not decrease the H: $\mathrm{Q}$ ratio values. Therefore, it can be said that even from this point of view, while keeping the right technique, squat exercise is suitable. There was probably no significant change in the $\mathrm{H}$ : $\mathrm{Q}$ ratio for several reasons. First, we compare the change in 1RM (specific exercise) with the change in the $\mathrm{H}$ : $\mathrm{Q}$ ratio (non-specific exercise), which was measured by an isokinetic dynamometer. For squatting (1RM), there was an average improvement of $21,62 \%$ for all participants; for dynamometer measurements, hamstring strength improved by $2,67 \%$, quadriceps strength by $1,86 \%$ at an angular speed of 60 degrees per second and 5,89\% for hamstrings and 6,64\% for quadriceps at 
an angular speed of 300 degrees per second. While squatting (specific exercise) is a multi-joint exercise within an open kinematic chain, dynamometer testing is a non-specific exercise within a closed kinematic chain. Another factor may be the fact that the strength of hamstrings and quadriceps was measured at concentric contraction.

Individual measurements (1RM and dynamometer) do not show similar results precisely because of the specificity and non-specificity of the exercise to the measurement. Baker, Wilson, $\&$ Carlyon (1994) confirm that the principle of specificity (motion structure, type of contraction, rate of contraction, resistance size, etc.) should be followed during testing.

Croix, EINagar, Iga, Ayala, \& James (2017), as some of many authors, show that women achieve lower H: Q ratio. Specifically, in their research, it was a $\mathrm{H}_{\mathrm{ecc}}: \mathrm{Q}_{\mathrm{con}}$ ratio where women achieved lower values at angular speeds of 120 and 240 degrees per second, but not at 60 degrees per second. At the same time, in their study, participants achieved a higher H: Q ratio at higher angular speeds, which corresponds to our results.

In this research, we can point out following limitations. One of the inconvenience was low number of trained subjects. It would be nearly impossible to use in this research more subjects due to insufficient equipment, lack of time and finances provided. It is also important to consider the fact that all trained and measured subjects were male students of Faculty of Sports Studies. We could get more relevant results in case of inclusion of common population. It would be interesting to measure also female subjects to compare final results for both sexes. Finally, it would be more efficient if we measured the strength of hamstrings during eccentric contractions and according to this measurement we might have work with functional $\mathrm{H}$ : $\mathrm{Q}$ ratio $\left(\mathrm{H}_{\mathrm{ecc}}: \mathrm{Q}_{\text {con }}\right)$, which would be more applicable. These limitations can be considered as recommendations for future researches.

\section{CONCLUSION}

In summary, we found out that the chosen strength training program had caused statistically significant progress in increase strength of lower limbs given $1 \mathrm{RM}$ values. The same training program didn't cause statistically significant changes of $\mathrm{H}_{\text {con }}: \mathrm{Q}_{\text {con }}$ ratio. To sum up, squats and their modifications are suitable exercises, but each subject's health condition needs to be considered.

The research was carried out as part of the MU project (ROZV/24/FSpS/01/2016).

\section{References}

Baechle, T. R., \& Earle, R. W. (2008). Essentials of strength training and conditioning. Champaign, IL: Human Kinetics.

Baker, D., Wilson, G., \& Carlyon, B. (1994). Generality versus specificity: a comparison of dynamic and isometric measures of strength and speed-strength. European Journal of Applied Physiology and Occupational Physiology, 68(4), 350-355.

Cacek, J. \& Grasgruber, P, (2008). Sportovní geny: antropometrie a fyziologie sportu, sport a rasa, doping. (1st ed.). Brno: Computer press.

Croix, M. D. S., ElNagar, Y. O., Iga, J., Ayala, F., \& James, D. (2017). The impact of joint angle and movement velocity on sex differences in the functional hamstring/quadriceps ratio. The Knee, 24(4), 745-750.

Delextrat, A., Gregory, J., \& Cohen, D. (2010). The use of the functional H: Q ratio to assess fatigue in soccer. International journal of sports medicine, 31(03), 192-197.

Hammerová, T., Králová T., Cacek, J., Kalina, T., Hlavoňová, Z., \& Ondráček, J. (2018). Impact of a strength intervention program on change in hamstring: quadriceps ratio. V M. Murfy, C. Boreham, G. de Vito, \& E- Tsolakidis, $23^{r d}$ Annual Congress of the European College of Sport Science, Book of Abstracts. Dublin: University College Dublin \& Ulster University.

Holcomb, W. R., Rubley, M. D., Lee, H. J., \& Guadagnoli, M. A. (2007). Effect of hamstring- emphasized resistance training on hamstring: kvadriceps strength ratios. The Journal of Strength \& Conditioning Research, 21(1), 41-47.

Chelly, M. S., Chérif, N., Amar, M. B., Hermassi, S., Fathloun, M., Bouhlel, E., ... \& Shephard, R. J. (2010). Relationships of peak leg power, 1 maximal repetition half back squat, and leg muscle volume to 5-m sprint performance of junior soccer players. The Journal of Strength \& Conditioning Research, 24(1), 266-271. 
Mausehund, L, Skard, AE, \& Krosshaug, T. (2019). Muscle activation in unilateral barbell exercises: Implications for strength training and rehabilitation. J Strength Cond Res 33(7S): S85-S94.

Stoppani, J. (2008). Velká kniha posilování: tréninkové metody a plány: 255 posilovacích cviků. Praha: Grada.

Tan, B. (1999). Manipulating resistance training program variables to optimize maximum strength in men: a review. The Journal of Strength \& Conditioning Research, 13(3), 289-304.

Toutoungi, D. E., Lu, T. W., Leardini, A., Catani, F., \& O’Connor, J. J. (2000). Cruciate ligament forces in the human knee during rehabilitation exercises. Clinical biomechanics, 15(3), 176-187.

Tsepis, E., Vagenas, G., Giakas, G., \& Georgoulis, A. (2004). Hamstring weakness as an indicator of poor knee function in ACL-deficient patients. Knee Surgery, Sports Traumatology, Arthroscopy, 12(1), 22-29. 